\title{
Molecular Markers and Cotton Genetic Improvement: Current Status and Future Prospects
}

\author{
Waqas Malik, ${ }^{1}$ Javaria Ashraf, ${ }^{1}$ Muhammad Zaffar Iqbal, ${ }^{2}$ \\ Asif Ali Khan, ${ }^{3}$ Abdul Qayyum, ${ }^{1}$ Muhammad Ali Abid, ${ }^{1}$ Etrat Noor, ${ }^{1}$ \\ Muhammad Qadir Ahmad, ${ }^{1}$ and Ghulam Hasan Abbasi ${ }^{4}$ \\ ${ }^{1}$ Department of Plant Breeding and Genetics, Faculty of Agricultural Sciences and Technology, \\ Bahauddin Zakariya University, Multan, Pakistan \\ ${ }^{2}$ Agricultural Biotechnology Research Institute, Ayub Agriculture Research Institute, Faisalabad, Pakistan \\ ${ }^{3}$ Department of Plant Breeding and Genetics, University of Agriculture, Faisalabad, Pakistan \\ ${ }^{4}$ University College of Agriculture and Environmental Sciences, The Islamia University of Bahawalpur, Bahawalpur, Pakistan
}

Correspondence should be addressed to Waqas Malik; waqasmalik@bzu.edu.pk

Received 21 July 2014; Accepted 17 September 2014; Published 23 October 2014

Academic Editor: Yeisoo Yu

Copyright (C) 2014 Waqas Malik et al. This is an open access article distributed under the Creative Commons Attribution License, which permits unrestricted use, distribution, and reproduction in any medium, provided the original work is properly cited.

\begin{abstract}
Narrow genetic base and complex allotetraploid genome of cotton (Gossypium hirsutum L.) is stimulating efforts to avail required polymorphism for marker based breeding. The availability of draft genome sequence of G. raimondii and G. arboreum and next generation sequencing (NGS) technologies facilitated the development of high-throughput marker technologies in cotton. The concepts of genetic diversity, QTL mapping, and marker assisted selection (MAS) are evolving into more efficient concepts of linkage disequilibrium, association mapping, and genomic selection, respectively. The objective of the current review is to analyze the pace of evolution in the molecular marker technologies in cotton during the last ten years into the following four areas: (i) comparative analysis of low- and high-throughput marker technologies available in cotton, (ii) genetic diversity in the available wild and improved gene pools of cotton, (iii) identification of the genomic regions within cotton genome underlying economic traits, and (iv) marker based selection methodologies. Moreover, the applications of marker technologies to enhance the breeding efficiency in cotton are also summarized. Aforementioned genomic technologies and the integration of several other omics resources are expected to enhance the cotton productivity and meet the global fiber quantity and quality demands.
\end{abstract}

\section{Introduction}

Cotton (Gossypium spp.) is considered as the foremost natural fiber and oil source worldwide, with an estimated production and utilization of $\sim 115$ million bales [1]. It is indigenous to tropical and subtropical regions and being cultivated on every continent excluding Antarctica [2]. The economic impact of the cotton industry throughout the world is about $\sim 500$ billion per year [3]. Despite its economic value, cotton has also an outstanding model system for studying cell elongation, polyploidization, cellulose, and biosynthesis of cell wall [4-6], because it is the only familiar plant that yields single-celled fiber [4].
Cotton belongs to genus Gossypium and family Malvaceae. The genus Gossypium has 45 diploid and 5 allotetraploid species and occur in semiarid and arid areas of Africa, Central and South America, Galapagos, Indian subcontinent, Australia, Arabia, and Hawaii [7]. These 50 species are allotted to 8 diploid genomes (A-G and $\mathrm{K}$ ) [8-10]. The $\mathrm{A}, \mathrm{B}, \mathrm{E}$, and $\mathrm{F}$ genomes naturally occur in Africa and Asia, while the $\mathrm{D}$ genome is indigenous to the America [11]. A third diploid clade, containing $\mathrm{C}, \mathrm{G}$, and $\mathrm{K}$, is found in Australia [12]. Currently cotton has only 4 cultivated species, two tetraploid species [G. hirsutum L. (AADD) and G. barbadense L. (AADD), $(2 n=4 x=52)]$ and two diploid species [G. arboreum L. $\left(\mathrm{A}_{2} \mathrm{~A}_{2}\right)$, and $G$. herbaceum $\mathrm{L}$. 
TABLE 1: Comparison of marker systems in cotton.

\begin{tabular}{|c|c|c|c|c|c|c|}
\hline Marker & $\begin{array}{c}\text { Template DNA } \\
\text { quantity }\end{array}$ & $\begin{array}{c}\text { Template DNA } \\
\text { quality }\end{array}$ & Genetics & Cost & Reliability & Reference \\
\hline RFLPs & High & High & Codominant & High & High & {$[26,47,166]$} \\
\hline RAPDs & Low & High & Dominant & Low & Low & {$[27,128]$} \\
\hline ISSRs & Low & Medium & Dominant & Low & Medium & {$[36,47]$} \\
\hline SSRs & Low & Moderate & Codominant & Low & High & {$[27,166]$} \\
\hline AFLPs & Medium & Moderate & Dominant & Moderate & High & {$[47,100,128]$} \\
\hline SNPs & Low & High & Codominant & Low & High & {$[92,166,167]$} \\
\hline GBS & Low & High & - & Low to moderate & High & {$[100,168]$} \\
\hline
\end{tabular}

$\left(\mathrm{A}_{1} \mathrm{~A}_{1}\right),(2 n=2 x=26]$ [13]. Cultivated tetraploid cotton evolved about 1-2 million years ago through hybridization of an A genome donor species ( $G$. herbaceum and G. arboreum) with a D genome ( $G$. raimondii and $G$. gossipioides) followed by polyploidization [14-16]. The progenitor allotetraploid "AD" diverged and gives rise to "AD" tetraploid species ( $G$. hirsutum L. and G. barbadense L.) [17]. G. hirsutum (Upland cotton or Mexican cotton) contributes 90\%; G. barbadense (Sea Island cotton or Egyptian cotton) produces $8 \%[18,19]$, G. herbaceum (Levant cotton) and G. arboreum (Tree cotton) together provide $2 \%$ of the world's cotton [20].

Tetraploid genome of cotton is relatively large and contains about 2200-3000 Mb of DNA [21, 22]. The intraspecific DNA polymorphism is low in this species [23, 24], which makes it a challenging crop for development of molecular markers. There is an undeniable need for highly polymorphic molecular markers if progress in plant breeding is to be made using marker-assisted breeding programs. Many extraordinary reviews have been written about the different classes of molecular markers used in plants and their application in construction of linkage map, QTL analysis and markerassisted selection [25-27]. The objectives of this review are as follows: (i) analysis of the evolution of molecular marker technologies in cotton genetics, (ii) genetic diversity in the wild and cultivated cotton gene pools, and (iii) overview of QTL mapping and marker assisted selection activities in cotton.

\section{Overview of Molecular Marker Technologies in Cotton}

Molecular markers are the firm landmarks in the genome of an organism rather than the normal genes because mostly they do not have the biological impacts and may or may not relate with phenotypic expression of a trait [26]. The development of the DNA markers is simple due to the availability of large scale genomic database [28]. In plant breeding, these markers are very helpful in recognition, characterization, identification of genetic variations, marker assisted selection (MAS), linkage mapping, and genomic fingerprinting [29], to remove linkage drag in backcrossing and to identify the traits which are not easy to measure by visual observation [30]. Molecular marker technologies can be classified into hybridization based, PCR based, and sequenced based markers on the basis of their working mechanism. Among these, PCR-based markers, that is, random amplified polymorphic DNA (RAPD) [23, 31, 32], amplified fragment length polymorphism (AFLP) [17, 33], simple sequence repeats microsatellites (SSRs) [34, 35], and inter simple sequence repeats (ISSRs) [36], represent the major class of markers in cotton genomics due to their high utility and exploitation. The comparison of different aspects of generally used molecular markers is given in Table 1 and brief description of these three classes of molecular markers is described below with special reference to cotton genetic.

2.1. Hybridization Based DNA Markers. Restriction fragment length polymorphism (RFLP) markers reveal the differences among individuals by variation in the size of DNA fragments produced by restriction enzymes [27]. These markers enabled DNA variations to be tested as substitutions of a single base in the recognition sequence of a restriction enzyme altered the length of resultant restriction fragments [37]. In this method cDNA or synthetic oligonucleotides are used as probes and DNA profiles are observed by hybridizing the restricted DNA fragment to a labeled probe (labeled with radioisotope). RFLPs can be used to examine the association between the closely related taxa, for study of introgression and gene flow between crops and weeds [38]. In various species of cotton, RFLP markers have been used to study the population genetics, evolution, and phylogenetic relationships [39]. Various reports are published on genetic mapping of cotton using RFLPs (restriction fragment length polymorphism) [40-42], and it was reported that in cotton 64\% RFLPs are codominant in nature [43]. Genetic diversity in upland cotton has also been examined using RFLP markers [38]. Molecular map of the cotton genome was first constructed using 705 RFLP loci and partitioned into 41 linkage groups [43]. The utility of RFLP markers in marker assisted selection (MAS) is reported and RFLP linked to resistance allele for pathogen of bacterial blight was validated [44]. RFLP markers are very complex and time and cost intensive technique which restricted it use, leading to development of less complicated techniques known as PCR base markers [26].

2.2. PCR Based Markers. PCR (polymerase chain reaction) is used for replication of small amount of DNA enzymatically without using the living organism. DNA polymerase, such as Taq polymerase, reads and synthesizes a new strand in $5^{\prime}-3^{\prime}$ direction using deoxynucleotide triphosphates (dNTP's). It 
can not only amplify small quantity of DNA, but degraded sources of DNA can also be amplified [45]. The reaction of PCR consists of many cycles of denaturation, annealing, and extension. Then, the PCR product can be visualized on agarose or polyacrylamide gels. PCR-based technology has been utilized widely in analysis of genetic diversity and recognition of DNA markers. Due to the simplicity and high chances of success in PCR, many approaches for production of PCR based molecular markers were described.

2.2.1. Random Amplified Polymorphic DNA, RAPD. RAPD is an old PCR based technique that infers DNA polymorphisms due to deletions or reorganization between the obligating sites of oligonucleotide primer in the genome [46]. In RAPDs, DNA fragments are amplified by the PCR reaction using random primers (usually of $10 \mathrm{bp}$ ) [47]. The sequence of the RAPD primers must fulfill the following criteria: (i) minimum $40 \%$ GC contents and (ii) absence of palindromic sequence [46]. A discrete DNA product is produced if these priming sites are within an amplifiable range of each other.

RAPD techniques have been used for many purposes including assessment of genetic variations in population [23, 48], DNA fingerprinting [49], and determining the relationship between the genotypes of different and same species [50]. In cotton RAPDs were used to distinguish the cotton varieties resistant to jassids, aphids, and mites [51]. RAPD marker (R-6592) for the male sterility gene has been identified in cotton [52]. RAPD techniques are also used to evaluate the genetic relationship among cotton genotypes [53], to identify the QTLs for stomatal conductance [54], and to construct linkage mapping in cotton.

2.2.2. Inter Simple Sequence Repeats, ISSR. In ISSRs, DNA fragments are amplified which present between two identical SSRs directed in contrary directions [47]. It allows the detection of polymorphism in inter SSR loci using primer (16-25 bp long) complimentary to a single SSR and anneal at either the $3^{\prime}$ or $5^{\prime}$ end [47], that can be di, tri, tetra or pentanucleotide [36]. The ISSR primers are commonly anchored at $3^{\prime}$ or $5^{\prime}$ end with 1 to 4 bases stretched into the flanking regions. The primers anchored at $3^{\prime}$ end produce more obvious bands as compared to anchored at $5^{\prime}$ end [36]. The technique of ISSR markers combines many benefits of AFLPs and SSRs with universality of RAPDs [55]. Generally the sequence of ISSR primers is larger as compare to RAPD primers, allowing higher annealing temperature which outcomes greater reproducibility of bands than RAPDs $[36,56]$. Amplification of ISSRs also revealed larger fragments number per primer than RAPDs [57]. Many earlier studies reported that ISSR markers were more informative than RAPDs for genetic diversity evaluation in different crop species [58,59].

The applications of ISSRs for different purposes depend on the diversity and frequencies of SSR within the particular genomes [60]. It is quickly being utilized by the research community in different areas of plant improvement, that is, in gene tagging, analysis of genetic diversity, and estimation of SSR motif [61-63].
2.2.3. Amplified Fragment Length Polymorphism, AFLP. AFLP markers were developed to overcome the problem of reproducibility connected to RAPDs [64]. This technique detects large number of loci in a single reaction of PCR [64, 65] and discovers large number of polymorphism dispersed across the genome [66]. In AFLP assays amplicon numbers are depend on (i) number of selective nucleotides in the primer, (ii) selective nucleotide motif, (iii) GC content, and (iv) physical genome size [26]. AFLP is an effective tool for the observation of genetic diversity [67], fingerprinting studies, and tagging of agronomic, seed, and fiber quality traits [68-70]. AFLP is a great valued technique for gene mapping studies due to their high abundance and random distribution throughout the genome [64]. A linkage map of cotton was developed using the AFLP and RAPD markers [71]. AFLP markers have also been used for analyzing the genetic diversity $[17,72]$ and map saturation in cotton $[19,73]$.

2.2.4. Microsatellites or Simple Sequence Repeats, SSR. These are di-, tri-, tetra- or pentatandom repeats of nucleotide, scattered abundantly in both noncoding and coding regions of a genome [29, 47]. Microsatellites are created from sphere where variants of repetitive DNA sequence are previously overrepresented [74]. The loci of these markers are highly transferable about 50\% across species [75]. For SSRs analysis forward and reverse primers are employed in PCR reaction that anneal to the template DNA at the $5^{\prime}$ and $3^{\prime}$ ends. Short repetitive DNA sequences furnish the basis for multi allelic, codominant PCR based molecular marker and found more polymorphic as compare to other DNA markers [27, 47].

Due to their greater polymorphism, SSRs are considered as an important marker system in fingerprinting, analysis of genetic diversity, molecular mapping and marker assisted selection [76]. The availability of SSR markers in the cotton genome make them useful in study of genetic diversity [20]. Furthermore, over 1000 SSR primers have been designed from available cotton DNA sequences in genomic libraries [77]. Cotton Gen database is the largest repository for the SSR markers and their mapping information (http://www .cottongen.org/find/mapped_markers).

(1) EST-SSRs. SSR markers obtained from ESTs (expressed sequence tags) are present in sequences of functional gene and directly associated with transcribed parts of DNA [78]. About $1-5 \%$ of the ESTs in different species of plants have SSRs of suitable length for development of markers [79]. As compare to genomic SSRs, EST-SSR markers have greater potential for transferability between the species [80]. ESTSSRs also have a greater possibility of being functionally linked with variations in gene expression than genomic SSRs [81]. Rising number of ESTs for cotton helped in the recognition of SSRs domains from the ESTs by data mining methods. Recently, several EST-SSRs have been mapped in cotton [82-85]. However, EST-SSRs exhibit low level of polymorphism than conventional SSRs [86].

(2) CAPS Microsatellites. Cleaved amplified polymorphic sequence (CAPS) technique is actually the combination of 
RFLP and PCR [87], in which DNA fragments are amplified through PCR, followed by digestion with a restriction enzyme [88]. Subsequently, polymorphisms arise from the variation in the incidence of restriction sites of identified alleles are detected by gel electrophoresis [88]. CAPS microsatellite and CAPS are technically alike and use of microsatellite spheres and flanking regions as a template may have a decisive improvement over the well-known DNA markers in crop species. CAPS microsatellites change the monomorphic markers into polymorphic markers which mostly inherited in codominant way [89] and exhibit high polymorphism between strongly related genotypes. Any base substitutions can be identified by CAPS microsatellites as the polymorphism exhibited by this technique is based on the sequence dissimilarities in the flanking regions aside from the microsatellite spheres. These markers also assist in the analysis of composite traits by gene mapping and propose the opportunity of identifying markers by physiological and biochemical characteristics of their gene products [86]. However, the CAPS markers are only developed where mutations create a recognition site for restriction enzyme [87].

\subsection{Sequence Based DNA Markers}

2.3.1. Single Nucleotide Polymorphism. Variations of single nucleotide (A, T, C, G) in sequence of individual genome are known as single nucleotide polymorphism or SNPs [26]. These may occur in the noncoding, coding and intergenic regions of the genome, so allowing the detection of the genes due to the variations in the sequences of nucleotides $[26,90]$ and these are either nonsynonymous or synonymous within the coding regions of the genome. Synonymous changes can alter mRNA splicing that result the changes in the phenotype of an individual [91].

SNP markers are important tool for linkage mapping, map based cloning and marker assisted selection due to the high level of polymorphism. The codominant nature of SNPs makes these markers able to distinguish the heterozygous and homozygous alleles [92]. Narrow genetic base and allotetraploid genome has made the discovery of SNPs difficult in cotton [93]. Recently, use of high throughput sequencing techniques have made it possible to detect great numbers of SNP markers $[94,95]$, including organisms with limited molecular studies $[96,97]$ and organisms with slight genetic variation such as cotton [85]. In cotton, many researches have been conducted to observe diversity, characterization and mapping of SNPs in the nucleotide sequence of Gossypium genome [98, 99]. Recently, an international collaborative effort has developed $70 \mathrm{~K}$ SNP chip based on Illumina Infinium genotyping assay (Unpublished data; http://www.cottongen.org/node/1287616). This high-throughput genotyping assay will be a resource that will be used globally by public and private breeders, geneticists, and other researchers to enhance cotton genetic analysis, breeding, genome sequence assembly, and many other uses. Similarly, Gene Chip cotton genome array comprising of 239777 probe sets representing 21485 cotton transcripts has been developed and under validation step before commercially available by
Affymetrix (http://www.affymetrix.com/products_services/ arrays/specific/cotton.affx). The sequences used for SNP chip development were selected from GenBank, dbEST and RefSeq contributed by the collaborators globally. These highthroughput technologies will be helpful for fine mapping and subsequent gene discovery for important economic traits in cotton. Additionally, these resources will provide foundations to initiate genomic selection studies in cotton, ultimately enhancing genetic gain from breeding.

2.3.2. Genotyping by Sequencing, GBS. Genotyping-by-sequencing (GBS) is a technique that simultaneously detects and genotypes the SNPs in a genome [100]. GBS was developed as a simple but strong access for reducing complexity in complex genomes [101]. The development of the GBS library is very simple. The original GBS method used a single restriction enzyme to capture the genomic sequence between restriction sites [101].

The choice of restriction enzyme is a crucial factor in GBS for covering the repetitive regions in the genomes. In the original GBS approach used in maize and barley, one restriction enzyme (RE) "ApeKI" was used which is methylation-sensitive to reduce the complexity of the genome and to choose hypomethylated sphere of the genome for sequencing [101]. A modified GBS approach was also developed in which two enzymes and a Y-adapter were used to generate "uniform" GBS libraries where Adapter 1 and Adapter 2 were on opposite ends of every fragment [102]. GBS is a multiple approach that can discover thousands of SNPs in an experiment and suitable for population studies, genomic selection, genetic mapping, germplasm characterization, and other breeding applications in different organisms [101-103]. GBS technique can also be employed in species of plants that do not have available reference genome. In these cases, the sequence tags can be deal as dominant markers for analysis [100].

\section{Overview of Marker Based Crop Improvement Efforts}

3.1. Genetic Diversity in Cotton. The success of any breeding program mainly depends on the availability of the genetic diversity in the germplasm resources. Understanding of the genetic relationships among plant genotypes is significant to know the complexity of available germplasm, to discover the differences in available genotypes and to build up useful conservation plans [104]. Thus, evaluation based on the molecular markers can give valuable insight into the genetic structure of a plant population, which helps in the development of new varieties [105]. The genetic diversity studies in cotton germplasm using different marker technologies are summarized in Table 2. A narrow genetic base is reported in cotton by several workers using different molecular markers [23, 38, 49, 106, 107].

RAPD and ISSR techniques have been utilized to analyze genetic diversity and hybridization and for the incident of somaclonal variations in various crops involving cotton [108112]. Five prominent studies were conducted to evaluate 


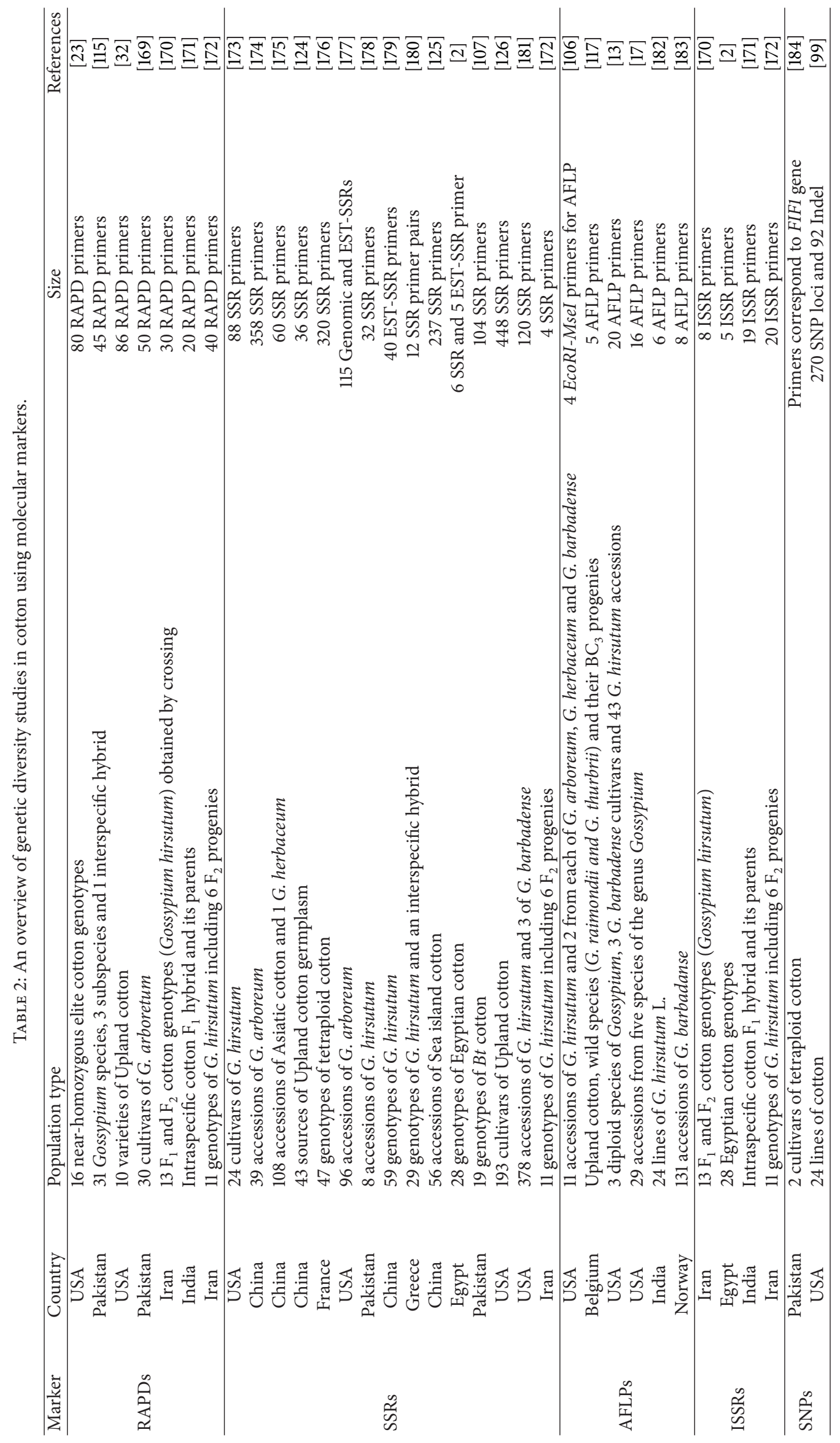


genetic diversity using RAPD markers during 90s. Genetic diversity of 16 elite homozygous genotypes obtained from the inter-specific hybridization was studied using 80 RAPD markers [23]. RAPD markers were used to differentiate the G. hirsutum lines from the G. arboretum [113]. Similarly, 25 short duration genotypes of cotton were analyzed using arbitrary primers [114]. Later, [115] studied genetic diversity of 31 Gossypium species, 3 subspecies, and 1 interspecific hybrid using 45 RAPD primers and the results showed that genetic relationship of many species is related to the center of origin. Recently, genetic diversity in 18 cotton genotypes of Pakistan studied by 5 RAPD primers showed that two diverse genotypes of cotton (CIM-240 and CIM-443) have resistance against cotton leaf curl virus [116].

AFLP technique was also used to distinguish the differences among diploid and tetraploid species of cotton by utilizing the variations in ribosomal RNA genes [106]. The genetic diversity between the upland cotton, wild species ( $G$. raimondii, G. thurberii, and G. sturtianum) and their $\mathrm{BC}_{3}$ progenies was evaluated using AFLP markers [117]. Intra- and interspecific relatedness of the G. barbadense, G. arboreum, G. raimondii, and G. hirsutum are determined by AFLPs which demonstrated its usefulness for genetic relatedness across wide range of species [17]. The relationship between the parents and four day neutral backcross generations of cotton was determined using 43 AFLP markers [68]. Comparative study was conducted to evaluate AFLP and RAPD techniques using 16 diploid cotton genotypes and it was concluded that AFLP markers are more efficient for polymorphism detection and for analyzing of genetic diversity as compared to RAPDs [72]. Similarly, genetic diversity of 26 Tanzanian cotton genotypes (Gossypium hirsutum L.) was studied using the AFLP markers [66]. The results of this study indicated the high values of genetic similarity which show the lower genetic diversity among Tanzanian cotton cultivars. Reference [65] mapped 98 AFLP markers and assigned 22 distinctive chromosomal positions using cytogenetic deletion stocks. Mapping information enhanced the utilization of AFLPs and can be used to saturate the existing marker frequency over different chromosomes.

In cotton, SSRs are considered as a new class of DNA markers which hastened cotton genetic diversity and mapping studies [27] and are important source to observe the transcribed genes [118]. There are multiple reports about using the SSR markers for genetic diversity. Reference [119] identified 71 SSR loci with 65 primer pairs and placed them on distinctive chromosomes of cotton. Genetic diversity among U.S. and Australian cultivars, and day neutral lines of $G$. hirsutum was also analyzed by SSR markers [120].

Further saturation of SSR markers was extended by addition of 204 markers which exhibited 261 segregating bands giving rise to 233 mapped loci in cotton [77]. Interspecific polymorphism between G. barbadense and G. hirsutum was also studied using SSR markers and results showed that polymorphism between species was high but it was low within species [121]. Reference [122] developed new SSR markers, analyzed the status of 23 chromosomes and found that the inter loci distance was $4.9 \mathrm{cM}$. Diversity among 52 different G. hirsutum cultivars was studied by 31 SSR primer pairs and successfully discriminated the 52 cultivars through broader allelic coverage [123]. Similarly, genetic diversity of 43 upland cotton varieties [124], 56 sea-island cotton accessions [125], 19 Bt cotton genotypes [107], 50 representative Pakistani genotypes [104], and 193 upland cotton cultivars [126] were evaluated using $36,237,104,70$, and 448 SSR markers, respectively. SSRs have also been used to assess the genetic purity of the cotton hybrids [127] and demonstrated as an effective tool for hybrid identification.

Recent developments in next generation sequencing (NGS) and RNA-seq technology have generated highthroughput sequence data which facilitated the identification of SNPs as effective and highly saturated markers for genetic studies in cotton. Genetic variations within and between the different species of cotton have been characterized by 1000 SNPs and 279 In-Dels from the 270 and 92 loci segregating in G. barbadense and G. hirsutum to provide mapped molecular markers for crosses within species and introgression of foreign germplasm in cotton [99]. A genome reduction experiment based on the restriction site conservation (GR-RSC) and previously generated assembly of express sequence tags (ESTs) were used to discover the SNPs in 4 accessions of G. hirsutum and G. barbadense. A total 11,834 and 1,679 non-genic and 4,327 genic SNPs were identified in the GR-RSC and EST assemblies using highly conservation parameters. The KASPer assays were used to target the 1,052 (704 nongenic and 348 genic) genome specific SNPs between the G. hirsutum accessions [93]. The assay then tested for the Mendelian segregation ratio in the $\mathrm{F}_{2}$ population derived from a cross of upland cotton ( $G$. hirsutum) cultivars.

3.2. QTLs Mapping for Important Economic Traits in Cotton. The regions in genomes to have genes linked with a quantitative trait are known as quantitative trait loci, QTLs [128], and the process of developing linkage maps and performing QTL analysis is referred to as QTL mapping [129, 130]. QTL analysis stands on the principal of identifying a connection among phenotype and genotype of markers [128]. The QTLs identified in cotton germplasm using different marker technologies are summarized in Table 3.

RFLPs have been widely used to map genes of economic interest in cotton. Previously, RFLP map of G. hirsutum and G. barbadense was used to map 14 QTLs for fiber related traits [131]. Similarly, genes influencing density of stem and leaf trichomes [132], high gossypol plant, and low seed gossypol contents [117] were confined by RFLP markers. Reference [131] developed an RFLP map of 261 markers distributed among 26 linkage groups using $\mathrm{F}_{2}$ plants from an interspecific cross. Another genetic linkage map was developed using RFLP markers, and 26 QTLs were recognized for agronomic and fiber quality traits [41]. Later on RFLP based QTL mapping was extended to leaf chlorophyll contents [133]. Backcross population of G. hirsutum and G. barbadense was used to map 28, 9, and 8 QTLs for fiber length, length uniformity, and short fiber contents, respectively, using the 262 RFLP markers [134].

RAPDs have also been widely used for QTL mapping in cotton; however, lack of reproducibility and unknown 


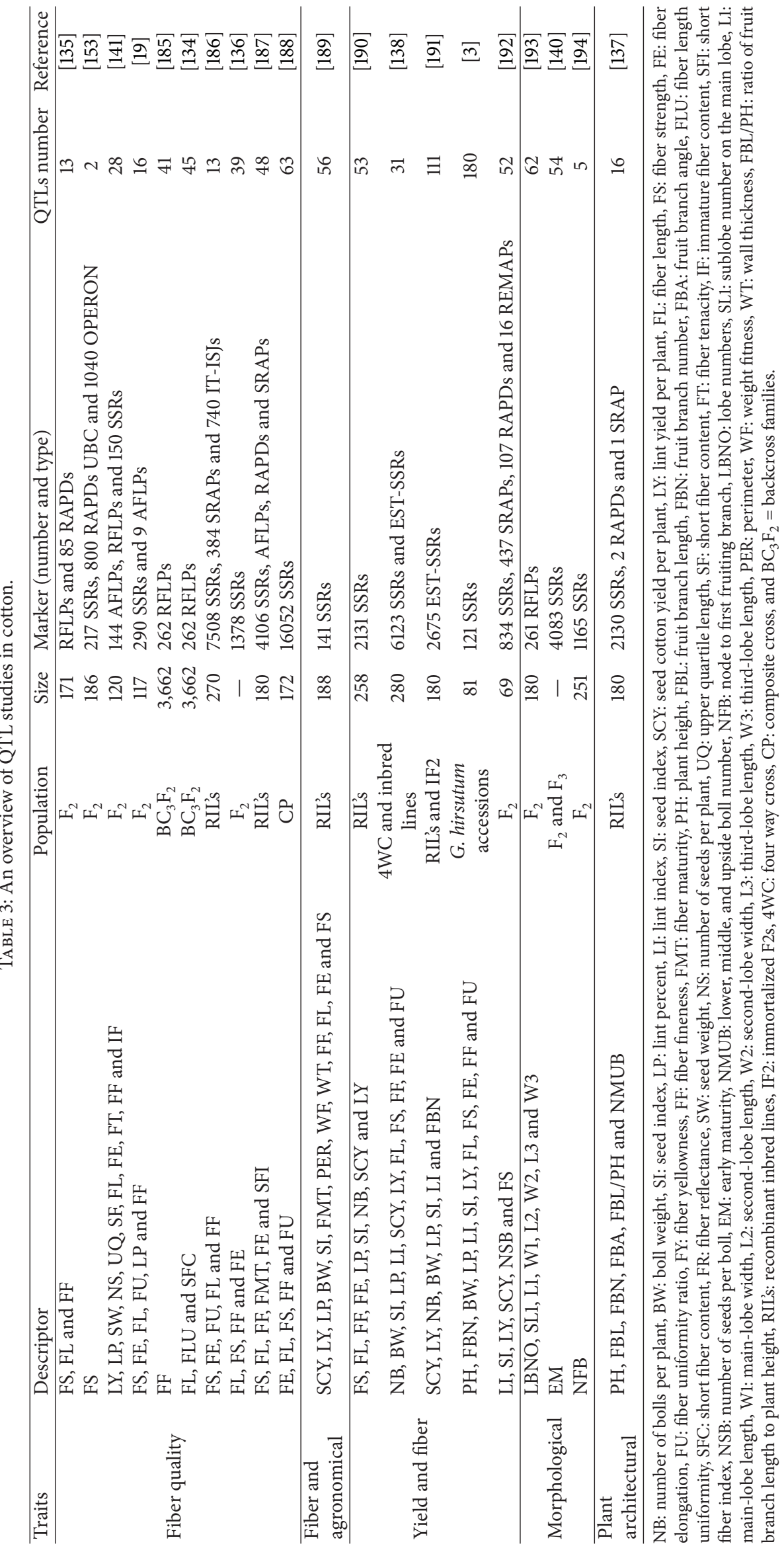


chromosomal positions remained main disadvantages which restricted the use of RAPDs in advanced studies. Reference [135] used 85 RAPD markers and identified 13 QTLs associated to the fiber quality in the $\mathrm{F}_{2}$ population derived from the G. hirsutum and G. barbadense cross. There are numerous studies on using the RAPDs for QTL mapping along with other molecular markers (Table 3). An extensive SSR genotyping was conducted over $\mathrm{F}_{2}$ populations from 3 diverse upland cotton genotypes using 1378 markers and 39 fiber related QTLs were identified [136]. Recombinant inbred lines (RILs) are also important mapping populations and several QTLs related to plant architecture [137], yield [3], and fiber quality [19] have been identified in upland cotton using RILs. About 31 QTLs linked to the yield and fiber quality traits are detected by wide array of SSR and EST SSR markers (6123) in 4 way cross populations developed from the 4 inbred lines of G. hirsutum [138]. A genetic linkage map of the tetraploid cotton was developed using 1601 pairs of SSR and 247 SNP markers [139]. The genetic map consisted of the 2072 loci covering $3380 \mathrm{~cm}$ of the cotton genome. Two $\mathrm{F}_{2}$ populations were generated by the crosses of upland cotton cultivars and 4083 SSR markers were used for QTL analysis, which detect 54 QTLs linked to early maturity [140].

A total of 144 primer combinations of AFLPs and 150 of SSRs were used to detect 28 QTLs related to the fiber traits [141]. To know the significant threshold for the LR statistics, permutation tests were carried out after which 7 QTLs remain significant. RIL lines developed from the intraspecific cross of upland cotton are used to detect the 12 epistatic and 4 main QTLs related to the plant architectural traits by 2130 SSR, 2 RAPD and 1 SRAP markers [137].

Conclusively, huge arrays of QTLs have been identified using multiple molecular marker technologies. Description of stable QTL from diverse generations, common QTL from various populations and homologous QTLs raises the information on the genetic base. Information about distribution of important QTLs in the genome of cotton is very important and promises the future strategy for marker assisted breeding. Cotton Gen serves as an important database for such information and currently this database has 988 QTLs for 25 different traits (http://www.cottongen.org/data/qtl) which can be surveyed according to objectivity.

\subsection{Genome Wide Association Studies (GWAS) in Cotton.} Association mapping, also known as linkage disequilibrium (LD) mapping, has appeared as a tool to determine the variation in complex traits using historical and evolutionary recombination actions at the population level [142]. In association mapping nonstructured populations are phenotyped and genotyped to identify the trait associated with marker [143]. This results into capture of wider recombination and higher resolution mapping as compared to linkage mapping [144]. The applications of association mapping for cotton assist extensive employment of natural genetic diversity conserved within the worldwide collections of cotton germplasm [145], as in other plant germplasm resources. Turning the efforts of gene-tagging from biparental QTL mapping to LDbased association study promise the productive employment of ex situ conserved genetic diversity of global germplasm resources of cotton [10]. The cotton genome may need few numbers of markers for productive associating mapping of complex traits, which is also reported for other crops [146]. Regarding the tetraploid genome of cotton with a total recombination length of about $5,200 \mathrm{~cm}$ and an average $400 \mathrm{~kb}$ per $\mathrm{cm}$ [22], the LD block sizes of $\sim 5-6 \mathrm{~cm}$ distance is sufficient to conduct an association mapping of different traits that would require a maximum of $\sim 1,000$ polymorphic markers for successful and reliable association mapping [147]. Extent of genome-wide LD and association mapping of fiber quality traits were reported using 95 SSR markers in 285 exotic accessions of $G$. hirsutum comprised of 208 landraces and 77 varieties [10]. Similarly, LD-based association mapping was conducted for fiber quality traits in $335 \mathrm{G}$. hirsutum germplasm using 202 SSR markers [147]. Progress in genome sequencing technology provides an opportunity to produce large size genotypic data, which supports association mapping over QTL mapping and because of this association mapping is becoming more common [148].

3.4. Marker Assisted Selection (MAS) in Cotton. Marker assisted selection (MAS) is a procedure by which a phenotype is selected on the basis of genotype of a marker [128]. Selecting the plants in the segregating population that have the suitable genes combinations is the important component of plant breeding [149]. Once the markers tightly linked to the genes have been detected, breeders may use particular DNA marker to identify the plants carry the genes [150]. The effectiveness and cost of MAS are influenced by the marker technique; therefore, it must be selected carefully [151]. During the past two decades, RAPDs techniques have been used for MAS for getting the glanded plants and glandless seeds in the interspecific population of $G$. sturtianum and other species [152]. It was exposed that DNA markers connected to the major QTL (QTLFS1) for fiber strength could be utilized in MAS to increase fiber strength of commercial varieties in segregating populations [153]. Some RAPD markers were developed into locus specific sequence characterized amplified region (SCAR) markers to screen the $\mathrm{BC}_{1} \mathrm{~F}_{4}$ upland cotton. For example, SCAR 1920 marker for the major fiber strength QTL was developed and has been used for selecting desirable genotypes [154]. Screening of the SNPs which are mapped on chromosome 10 recognized extra 3 SNP markers that were associated with blue disease resistance gene $(C b d)$ which were employed to efficiently characterize a trait allowing MAS for strong levels of blue disease resistance in cotton breeding programs [155].

\section{Cotton Draft Genome and Its Implication}

The increasing information of DNA sequencing allows the discovery of genes and molecular markers associated with different traits, opening new avenues for crop improvement [148]. Sequencing of DNA promises to display the spectrum of diversity in the genus Gossypium. The tetraploid cotton species $(2 n=4 x=52)$, such as $G$. hirsutum and $G$. bar- 
badense, are thought to have developed by an allopolyploidization that happened nearly 1-2 million years ago, in which a D-genome species is pollen parent and species of an A-genome is maternal parent $[12,156]$. It is essential to have a basic awareness of the structure of the component genomes to understand the cultivated polyploid genomes, their evolution, and interaction between their subgenomes. Toward the long-term aim of characterizing the diversity among cotton genomes, the cotton geneticists have prioritized the $\mathrm{D}$ genome progenitor $G$. raimondii for complete sequencing. G. raimondii has a $\sim 880 \mathrm{Mb}$ genome [157], the smallest genome in the genus Gossypium at $\sim 60 \%$ of the size of diploid Agenome and $40 \%$ of the tetraploids [158]. A physical map of G. raimondii genome was assembled and several evidences referred that the G. raimondii genome is composed of two different qualitative components, one that is gene-rich and another that is repeat-rich [158]. About 40,976 protein coding genes, and 2,355 syntenic blocks identified in the genome of G. raimondii [159]. Similarly, the sequencing and assembling of G. arboreum genome depicted that $68.5 \%$ of the genome is covered by repetitive DNA sequences and about 41,330 protein-coding genes were predicted in the genome of $G$. arboreum [160].

\section{Future Prospects}

Cotton is a major source of foreign exchange for many countries around the globe; therefore, major focus remains the enhancement of yield and quality of fiber. This challenge can be accomplished by introducing new alleles from wild species $[161,162]$ and use of modern molecular technologies helping in increasing genetic gain of economic traits. In this scenario, it is believed that sequencing of the G. raimondii [159] and G. arboreum [160] draft genomes will facilitate the gene discovery of important traits. These genome resources can also be used for discovery of high-throughput marker platforms like Select SNP arrays. These high-throughput DNA markers will be helpful in recognizing the cotton genotypes carrying desired characters and was successfully used not only to study the genetic diversity but to develop linkage maps and mapping agronomic traits $[12,20]$, which are necessary for acceleration of varietal development. Although the QTL mapping for the various traits, that is, fiber yield and quality [131], drought tolerance [133], disease resistance $[163,164]$, and pests resistance [165] have been accomplished in cotton but these may not be helpful to clone causal genes due to lower marker densities. In general, the choice of a molecular marker technique is based on reliability, statistical power, and level of polymorphisms. Since their invention they are being continuously modified for improved utility to solve many problems and to bring forth automation. When these markers techniques reach a greater degree of automation then it will be suitable to use DNA markers directing to a new "Green Revolution" in the agricultural world.

Presently, the enormous development of more efficient DNA markers will go on in the future, because they can serve as an important tool for the plant breeders and geneticists to develop the cultivars of cotton that are demanded by the society. It has been proposed that SNPs marker will have large influence on MAS and mapping studies in future due to high abundance and development of sophisticated detection system [195]. GBS will clearly become the marker genotyping platform in coming years. So the development of novel markers such as GBS and SNPs and the accessibility of modern technologies such as DNA Chips and microarrays hasten genome mapping and subsequent gene discovery in the cotton for efficient cotton varietal development.

\section{Conflict of Interests}

The authors declare that there is no conflict of interests regarding the publication of this paper.

\section{Acknowledgment}

We are highly thankful to Dr. Awais Rasheed (CIMMYT, China) for his valued inputs and comments.

\section{References}

[1] USDA, Cotton and Wool Year book, Dataset, 2011, http://usda .mannlib.cornell.edu/MannUsda/viewDocumentInfo.do?documentID=128.

[2] K. F. Abdellatif, Y. A. Khidr, Y. M. Mansy, M. M. Lawendey, and Y. A. Soliman, "Molecular diversity of Egyptian cotton (Gossypium barbadense L.) and its relation to varietal development," Journal of Crop Science and Biotechnology, vol. 15, pp. 93-99, 2012.

[3] T. Zhang, N. Qian, X. Zhu et al., "Variations and transmission of QTL alleles for yield and fiber qualities in upland cotton cultivars developed in China," PLoS ONE, vol. 8, no. 2, Article ID e57220, 2013.

[4] H. J. Kim and B. A. Triplett, "Cotton fiber growth in planta and in vitro. Models for plant cell elongation and cell wall biogenesis," Plant Physiology, vol. 127, no. 4, pp. 1361-1366, 2001.

[5] Y.-L. Ruan, D. J. Llewellyn, and R. T. Furbank, "Suppression of sucrose synthase gene expression represses cotton fiber cell initiation, elongation, and seed development," Plant Cell, vol.15, no. 4, pp. 952-964, 2003.

[6] Y.-M. Qin and Y.-X. Zhu, "How cotton fibers elongate: a tale of linear cell-growth mode," Current Opinion in Plant Biology, vol. 14, no. 1, pp. 106-111, 2011.

[7] P. A. Fryxell, "A revised taxonomic interpretation of Gossypium L. ( Malvaceae )," Rheedea, vol. 2, pp. 108-165, 1992.

[8] J. O. Beasley, "The production of polyploids in gossypium," Journal of Heredity, vol. 31, no. 1, pp. 39-48, 1940.

[9] J. E. Endrizzi, E. L. Turcotte, and R. J. Kohel, “Genetics, cytology and evolution of Gossypium," Advances in Genetics, vol. 23, pp. 271-375, 1985.

[10] I. Y. Abdurakhmonov, R. J. Kohel, J. Z. Yu et al., "Molecular diversity and association mapping of fiber quality traits in exotic G. hirsutum L. germplasm," Genomics, vol. 92, no. 6, pp. 478487, 2008.

[11] J. F. Wendel and R. C. Cronn, "Polyploidy and the evolutionary history of cotton," Advances in Agronomy, vol. 78, pp. 139-186, 2003. 
[12] Z. J. Chen, B. E. Scheffler, E. Dennis et al., "Toward sequencing cotton (Gossypium) genomes," Plant Physiology, vol. 145, no. 4, pp. 1303-1310, 2007.

[13] M. J. Iqbal, O. U. K. Reddy, K. M. El-Zik, and A. E. Pepper, "A genetic bottleneck in the 'evolution under domestication' of upland cotton Gossypium hirsutum L. examined using DNA fingerprinting," Theoretical and Applied Genetics, vol. 103, no. 4, pp. 547-554, 2001.

[14] J. O. Beasley, "The origin of American tetraploid Gossypium species," The American Naturalist, vol. 74, pp. 285-286, 1940.

[15] J. O. Beasley, "Meiotic chromosome behavior in species, species hybrids, haploids and induced polyploids of Gossypium," Genetics, vol. 27, no. 1, pp. 25-54, 1942.

[16] J. F. Wendel, C. L. Brubaker, and A. E. Percival, "Genetic diversity in Gossypium hirsutum and the origin of upland cotton," American Journal of Botany, vol. 79, no. 11, pp. 1291-1310, 1992.

[17] A. M. Abdalla, O. U. K. Reddy, K. M. El-Zik, and A. E. Pepper, "Genetic diversity and relationships of diploid and tetraploid cottons revealed using AFLP," Theoretical and Applied Genetics, vol. 102, no. 2-3, pp. 222-229, 2001.

[18] X. L. Song, X. Z. Sun, T. Z. Zhang, and H. G. Wang, "Advances on genetic diversity of cotton (Gossypium)," Acta Botanica Boreali-Occidentalia Sinica, vol. 24, pp. 2393-2397, 2004.

[19] Z.-S. Zhang, Y.-H. Xiao, M. Luo et al., "Construction of a genetic linkage map and QTL analysis of fiber-related traits in upland cotton (Gossypium hirsutum L.)," Euphytica, vol. 144, no. 1-2, pp. 91-99, 2005.

[20] H.-B. Zhang, Y. Li, B. Wang, and P. W. Chee, "Recent advances in cotton genomics," International Journal of Plant Genomics, vol. 2008, Article ID 742304, 20 pages, 2008.

[21] K. Arumuganathan and E. D. Earle, "Nuclear DNA content of some important plant species," Plant Molecular Biology Reporter, vol. 9, no. 3, pp. 208-218, 1991.

[22] A. H. Paterson and R. H. Smith, "Future horizons: biotechnology of cotton improvement," in Cotton: Origin, History, Technology, and Production, pp. 415-432, John Wiley \& Sons, New York, NY, USA, 1999.

[23] V. Tatineni, R. G. Cantrell, and D. D. Davis, "Genetic diversity in elite cotton germplasm determined by morphological characteristics and RAPDs," Crop Science, vol. 36, no. 1, pp. 186-192, 1996.

[24] C. L. Brubaker and J. F. Wendel, "RFLP diversity in cotton," in Genetic Improvement of Cotton, Emerging Technologies, pp. 81101, Science Publishers, Enfield, NH, USA, 2001.

[25] N. D. Young, "Constructing a plant genetic linkage map with DNA markers," in DNA-Based Markers in Plants, pp. 3957, Kluwer Academic Publishers, Dordrecht, The Netherlands, 1994.

[26] M. Agarwal, N. Shrivastava, and H. Padh, "Advances in molecular marker techniques and their applications in plant sciences," Plant Cell Reports, vol. 27, no. 4, pp. 617-631, 2008.

[27] S. Preetha and T. S. Raveendren, "Molecular marker technology in cotton," Biotechnology and Molecular Biology Reviews, vol. 3 , no. 2, pp. 32-45, 2008.

[28] J. R. Andersen and T. Lübberstedt, "Functional markers in plants," Trends in Plant Science, vol. 8, no. 11, pp. 554-560, 2003.

[29] R. K. Kalia, M. K. Rai, S. Kalia, R. Singh, and A. K. Dhawan, "Microsatellite markers: an overview of the recent progress in plants," Euphytica, vol. 177, no. 3, pp. 309-334, 2011.
[30] N. Appleby, D. Edwards, and J. Batley, "New technologies for ultra-high throughput genotyping in plants," Methods in Molecular Biology, vol. 513, pp. 19-39, 2009.

[31] Q. H. Xu, X. L. Zhang, and Y. C. Nie, "Genetic diversity evaluation of cultivars (G. hirsumtum L.) from the Changjiang river valley and Tellow river valley by RAPD markers," Acta Genetica Sinica, vol. 28, no. 7, pp. 683-690, 2001.

[32] H. J. Lu and G. O. Myers, "Genetic relationships and discrimination of ten influential upland cotton varieties using RAPD markers," Theoretical and Applied Genetics, vol. 105, no. 2-3, pp. 325-331, 2002.

[33] I. Álvarez and J. F. Wendel, "Cryptic interspecific introgression and genetic differentiation within Gossypium aridum (Malvaceae) and its relatives," Evolution, vol. 60, no. 3, pp. 505-517, 2006.

[34] S. Liu, R. G. Cantrell, J. C. McCarty Jr., and J. M. Stewart, "Simple sequence repeat-based assessment of genetic diversity in cotton race stock accessions," Crop Science, vol. 40, no. 5, pp. 1459-1469, 2000.

[35] L. F. Zhu, X. L. Zhang, and Y. C. Nie, "Analysis of genetic diversity in upland cotton (Gossypium hirsutum L.) cultivars from China and foreign countries by RAPDs and SSRs," Journal of Agricultural Biotechnology, vol. 11, pp. 450-455, 2003.

[36] M. P. Reddy, N. Sarla, and E. A. Siddiq, "Inter simple sequence repeat (ISSR) polymorphism and its application in plant breeding," Euphytica, vol. 128, no. 1, pp. 9-17, 2002.

[37] C. Schlötterer, "The evolution of molecular markers-just a matter of fashion?" Nature Reviews Genetics, vol. 5, no. 1, pp. 63-69, 2004.

[38] C. L. Brubaker and J. F. Wendel, "Reevaluating the origin of domesticated cotton (Gossypium hirsutum; Malvaceae) using nuclear restriction fragment length polymorphisms (RFLPs)," American Journal of Botany, vol. 81, no. 10, pp. 1309-1326, 1994.

[39] Z. H. Yu, Y. H. Park, G. R. Lazo, and R. J. Kohel, Molecular Mapping of the Cotton Genome. Agron, Abstracts, ASA, Madison, Wis, USA, 1997.

[40] C. L. Brubaker, A. H. Paterson, and J. F. Wendel, "Comparative genetic mapping of allotetraploid cotton and its diploid progenitors," Genome, vol. 42, no. 2, pp. 184-203, 1999.

[41] M. Ulloa and W. R. Meredith Jr., "Genetic linkage map and QTL analysis of agronomic and fiber traits in an intraspecific population," Journal of Cotton Science, vol. 4, no. 3, pp. 161-170, 2000.

[42] M. Ulloa, W. R. Meredith Jr., Z. W. Shappley, and A. L. Kahler, "RFLP genetic linkage maps from four $\mathrm{F}_{2.3}$ populations and a joinmap of Gossypium hirsutum L," Theoretical and Applied Genetics, vol. 104, no. 2-3, pp. 200-208, 2002.

[43] A. J. Reinisch, J.-M. Dong, C. L. Brubaker, D. M. Stelly, J. F. Wendel, and A. H. Paterson, "A detailed RFLP map of cotton, Gossypium hirsutum $x$ Gossypium barbadense: chromosome organization and evolution in a disomic polyploid genome," Genetics, vol. 138, no. 3, pp. 829-847, 1994.

[44] R. J. Wright, P. M. Thaxton, K. M. El-Zik, and A. H. Paterson, "D-subgenome bias of $\mathrm{Xcm}$ resistance genes in tetraploid Gossypium (cotton) suggests that polyploid formation has created novel avenues for evolution," Genetics, vol. 149, no. 4, pp. 1987-1996, 1998.

[45] H. A. Erlich, PCR Technology: Principles and Applications for DNA Amplification, W. H. Freeman, New York, NY, USA, 1991.

[46] J. G. K. Williams, A. R. Kubelik, K. J. Livak, J. A. Rafalski, and S. V. Tingey, "DNA polymorphisms amplified by arbitrary primers 
are useful as genetic markers," Nucleic Acids Research, vol. 18, no. 22, pp. 6531-6535, 1990.

[47] S. Khanam, A. Sham, J. L. Bennetzen, and M. A. M. Aly, "Analysis of molecular marker-based characterization and genetic variation in date palm (Phoenix Dactylifera L.)," Australian Journal of Crop Science, vol. 6, no. 8, pp. 1236-1244, 2012.

[48] K. J. Chalmers, R. Waugh, J. I. Sprent, A. J. Simons, and W. Powell, "Detection of genetic variation between and within populations of Gliricidia sepium and G. maculata using RAPD markers," Heredity, vol. 69, pp. 465-472, 1992.

[49] D. S. Multani and B. R. Lyon, "Genetic fingerprinting of Australian cotton cultivars with RAPD markers," Genome, vol. 38, no. 5, pp. 1005-1008, 1995.

[50] M. K. Wajahatullah and J. M. Stewart, "Genomic affinity among Gossypium subgenus Sturtia species by RAPD analysis," in Proceeding of the Beltwide Cotton Conference, National Cotton Council, p. 452, Memphis, Tenn, USA, 1997.

[51] C. D. Geng, Z. Z. Gong, J. Q. Huang, and Z. C. Zhang, "Identification of difference between cotton cultivars (G. hirsutum) using the RAPD method," Jiangsu Journal of Agricultural Sciences, vol. 11, no. 4, pp. 21-24, 1995.

[52] T. H. Lan, C. G. Cook, and A. H. Paterson, "Identification of a RAPD marker linked to male fertility restoration gene in cotton (Gossypium hirsutum L.)," Journal of Agricultural Genomics, vol. 1, pp. 1-5, 1999.

[53] B. Shu, K. Fenling, Z. Y. Yao, Z. G. Mei, Z. Q. Yuan, and W. X. Gang, "Genetic diversity analysis of representative elite cotton varieties in three main cotton regions in China by RAPD and its relation with agronomic characteristics," Scientia Agricultura Sinica, vol. 34, pp. 597-603, 2001.

[54] M. Ulloa, R. G. Cantrell, R. G. Percy, E. Zeiger, and Z. Lu, "QTL analysis of stomatal conductance and relationship to lint yield in an interspecific cotton," Journal of Cotton Science, vol. 4, no. 1, pp. 10-18, 2000.

[55] B. Bornet and M. Branchard, "Nonanchored inter simple sequence repeat (ISSR) markers: reproducible and specific tools for genome fingerprinting," Plant Molecular Biology Reporter, vol. 19, no. 3, pp. 209-215, 2001.

[56] T. M. Culley and A. D. Wolfe, "Population genetic structure of the cleistogamous plant species Viola pubescens Aiton (Violaceae), as indicated by allozyme and ISSR molecular markers," Heredity, vol. 86, no. 5, pp. 545-556, 2000.

[57] J. B. Wang, "ISSR markers and their applications in plant genetics," Yi Chuan, vol. 24, no. 5, pp. 613-616, 2002.

[58] T. Nagaoka and Y. Ogihara, "Applicability of inter-simple sequence repeat polymorphisms in wheat for use as DNA markers in comparison to RFLP and RAPD markers," Theoretical and Applied Genetics, vol. 94, no. 5, pp. 597-602, 1997.

[59] M. Z. Galván, B. Bornet, P. A. Balatti, and M. Branchard, "Inter simple sequence repeat (ISSR) markers as a tool for the assessment of both genetic diversity and gene pool origin in common bean (Phaseolus vulgaris L.)," Euphytica, vol. 132, no. 3, pp. 297-301, 2003.

[60] A. Shi, S. Kantartzi, M. Mmbaga, and P. Chen, "Development of ISSR PCR markers for diversity study in dogwood (Cornus spp.)," Agriculture and Biology Journal of North America, vol. 1, pp. 189-194, 2010.

[61] M. W. Blair, O. Panaud, and S. R. McCouch, "Inter-simple sequence repeat (ISSR) amplification for analysis of microsatellite motif frequency and fingerprinting in rice (Oryza sativa L.)," Theoretical and Applied Genetics, vol. 98, no. 5, pp. 780-792, 1999.
[62] B. Bornet, C. Muller, F. Paulus, and M. Branchard, "Highly informative nature of inter simple sequence repeat (ISSR) sequences amplified using tri- and tetra-nucleotide primers from DNA of cauliflower (Brassica oleracea var. botrytis L.)," Genome, vol. 45, no. 5, pp. 890-896, 2002.

[63] M. Sica, G. Gamba, S. Montieri, L. Gaudio, and S. Aceto, "ISSR markers show differentiation among Italian populations of Asparagus acutifolius L," BMC Genetics, vol. 6, article 17, 2005.

[64] P. Vos, R. Hogers, M. Bleeker et al., "AFLP: a new technique for DNA fingerprinting," Nucleic Acids Research, vol. 23, no. 21, pp. 4407-4414, 1995.

[65] G. O. Myers, B. Jiang, M. W. Akash, A. Badigannavar, and S. Saha, "Chromosomal assignment of AFLP markers in upland cotton (Gossypium hirsutum L.)," Euphytica, vol. 165, no. 2, pp. 391-399, 2009.

[66] K. Lukonge, L. Hersalman, and M. T. Labuschagne, "Genetic diversity of tanzanian cotton revealed by AFLP analysis," in Proceedings of the African Crop Science Conference, vol. 8, pp. 773-776, 2007.

[67] N. Murtaza, "Cotton genetic diversity study by AFLP markers," Electronic Journal of Biotechnology, vol. 9, no. 4, pp. 456-460, 2006.

[68] M. Zhong, J. C. McCarty, J. N. Jenkins, and S. Saha, "Assessment of day-neutral backcross populations of cotton using AFLP markers," Journal of Cotton Science, vol. 6, no. 2, pp. 97-103, 2002.

[69] A. Rakshit, S. Rakshit, J. Singh et al., "Association of AFLP and SSR markers with agronomic and fibre quality traits in Gossypium hirsutum L," Journal of Genetics, vol. 89, no. 2, pp. 155-162, 2010.

[70] A. Badigannavar and G. Myers, "Genetic analysis of AFLP markers associated with seed quality traits in upland cotton (Gossypium hirsutum)," in Beltwide Cotton Conferences, New Orleans, La, USA, 2010.

[71] M. K. Altaf, J. M. C. D. Stewart, M. K. Wajahatullah, J. Zhang, and R. G. Cantrell, "Molecular and morphological genetics of a trispecies F2 population of cotton," in Proceedings of the Beltwide Cotton Conferences, vol. 1, pp. 448-452, New Orleans, La, USA, January 1997.

[72] M. K. Rana and K. V. Bhat, "A comparison of AFLP and RAPD markers for genetic diversity and cultivar identification in cotton," Journal of Plant Biochemistry and Biotechnology, vol. 13, no. 1, pp. 19-24, 2004.

[73] J.-M. Lacape, T.-B. Nguyen, S. Thibivilliers et al., "A combined RFLP-SSR-AFLP map of tetraploid cotton based on a Gossypium hirsutum $\times$ Gossypium barbadense backcross population," Genome, vol. 46, no. 4, pp. 612-626, 2003.

[74] D. Tautz, M. Trick, and G. A. Dover, "Cryptic simplicity in DNA is a major source of genetic variation," Nature, vol. 322, no. 6080, pp. 652-656, 1986.

[75] S. Saha, J. Wu, J. N. Jenkins et al., "Breeding and genetics: effect of chromosome substitutions from Gossypium barbadense L. 379 into G. hirsutum L. TM-1 on agronomic and fiber traits," Journal of Cotton Science, vol. 8, no. 3, pp. 162-169, 2004.

[76] O. U. K. Reddy, A. E. Pepper, I. Abdurakhmonov et al., "New dinucleotide and trinucleotide microsatellite marker resources for cotton genome research," Journal of Cotton Science, vol. 5, no. 2, pp. 103-113, 2001.

[77] T. B. Nguyen, M. Giband, P. Brottier, A. M. Risterucci, and J. M. Lascape, "Wide coverage of the tetraploid cotton genome using newly developed microsatellite markers," Theoretical and Applied Genetics, vol. 109, no. 1, pp. 167-175, 2004. 
[78] R. K. Varshney, A. Graner, and M. E. Sorrells, "Genic microsatellite markers in plants: features and applications," Trends in Biotechnology, vol. 23, no. 1, pp. 48-55, 2005.

[79] R. V. Kantety, M. La Rota, D. E. Matthews, and M. E. Sorrells, "Data mining for simple sequence repeats in expressed sequence tags from barley, maize, rice, sorghum and wheat," Plant Molecular Biology, vol. 48, no. 5-6, pp. 501-510, 2002.

[80] H.-Y. Zhu, T.-Z. Zhang, L.-M. Yang, and W.-Z. Guo, "EST-SSR sequences revealed the relationship of D-genome in diploid and tetraploid Species in Gossypium," Plant Science, vol. 176, no. 3, pp. 397-405, 2009.

[81] L. F. Gao, R. L. Jing, N. X. Huo et al., "One hundred and one new microsatellite loci derived from ESTs (EST-SSRs) in bread wheat," Theoretical and Applied Genetics, vol. 108, no. 7, pp. 13921400, 2004.

[82] P. W. Chee, J. Rong, D. Williams-Coplin, S. R. Schulze, and A. H. Paterson, "EST derived PCR-based markers for functional gene homologues in cotton," Genome, vol. 47, no. 3, pp. 449462, 2004.

[83] Z.-G. Han, W.-Z. Guo, X.-L. Song, and T.-Z. Zhang, "Genetic mapping of EST-derived microsatellites from the diploid Gossypium arboreum in allotetraploid cotton," Molecular Genetics and Genomics, vol. 272, no. 3, pp. 308-327, 2004.

[84] Z. Han, C. Wang, X. Song et al., "Characteristics, development and mapping of Gossypium hirsutum derived EST-SSRs in allotetraploid cotton," Theoretical and Applied Genetics, vol. 112, no. 3, pp. 430-439, 2006.

[85] J. A. Udall, J. M. Swanson, K. Haller et al., "A global assembly of cotton ESTs," Genome Research, vol. 16, no. 3, pp. 441-450, 2006.

[86] A. G. Ince, M. Karaca, and A. N. Onus, "CAPS-microsatellites: use of CAPS method to convert non-polymorphic microsatellites into useful markers," Molecular Breeding, vol. 25, no. 3, pp. 491-499, 2010.

[87] K. Semagn, Å. Bjørnstad, and M. N. Ndjiondjop, "An overview of molecular marker methods for plants," African Journal of Biotechnology, vol. 5, no. 25, pp. 2540-2568, 2006.

[88] A. Konieczny and F. M. Ausubel, "A procedure for mapping Arabidopsis mutations using co-dominant ecotype-specific PCRbased markers," Plant Journal, vol. 4, no. 2, pp. 403-410, 1993.

[89] M. Karaca and A. G. Ince, "New non-redundant microsatellite and CAPS-microsatellite markers for cotton (Gossypium L.)," Turkish Journal of Field Crops, vol. 16, no. 2, pp. 172-178, 2011.

[90] K. O. Ayeh, "Expressed sequence tags (ESTs) and single nucleotide polymorphisms (SNPs): emerging molecular marker tools for improving agronomic traits in plant biotechnology," African Journal of Biotechnology, vol. 7, no. 4, pp. 331-341, 2008.

[91] I. Richard and J. S. Beckmann, "How neutral are synonymous codon mutations?" Nature genetics, vol. 10, no. 3, article 259, 1995.

[92] T. Shaheen, M. Asif, and Y. Zafar, "Single nucleotide polymorphism analysis of MT-SHSP gene of Gossypium arboreum and its relationship with other diploid cotton genomes, G. hirsutum and Arabidopsis thaliana," Pakistan Journal of Botany, vol. 41, no. 1, pp. 177-183, 2009.

[93] R. L. Byers, D. B. Harker, S. M. Yourstone, P. J. Maughan, and J. A. Udall, "Development and mapping of SNP assays in allotetraploid cotton," Theoretical and Applied Genetics, vol. 124, no. 7, pp. 1201-1214, 2012.

[94] W. B. Barbazuk, S. J. Emrich, H. D. Chen, L. Li, and P. S. Schnable, "SNP discovery via 454 transcriptome sequencing," Plant Journal, vol. 51, no. 5, pp. 910-918, 2007.
[95] C. P. van Tassell, T. P. L. Smith, L. K. Matukumalli et al., "SNP discovery and allele frequency estimation by deep sequencing of reduced representation libraries," Nature Methods, vol. 5, no. 3, pp. 247-252, 2008.

[96] N. A. Baird, P. D. Etter, T. S. Atwood et al., "Rapid SNP discovery and genetic mapping using sequenced RAD markers," PLoS ONE, vol. 3, no. 10, Article ID e3376, 2008.

[97] P. C. Bundock, F. G. Eliott, G. Ablett et al., "Targeted single nucleotide polymorphism (SNP) discovery in a highly polyploid plant species using 454 sequencing," Plant Biotechnology Journal, vol. 7, no. 4, pp. 347-354, 2009.

[98] C. An, S. Saha, J. N. Jenkins et al., "Cotton (Gossypium spp.) R2R3-MYB transcription factors SNP identification, phylogenomic characterization, chromosome localization, and linkage mapping," Theoretical and Applied Genetics, vol. 116, no. 7, pp. 1015-1026, 2008.

[99] A. van Deynze, K. Stoffel, M. Lee et al., "Sampling nucleotide diversity in cotton," BMC Plant Biology, vol. 9, article 125, 2009.

[100] R. R. Mir, P. J. Hiremath, O. Riera-Lizarazu, and R. K. Varshney, "Evolving molecular marker technologies in plants: from RFLPs to GBS," in Diagnostics in Plant Breeding, vol. 11, pp. 229-247, Springer, Amsterdam, The Netherlands, 2013.

[101] R. J. Elshire, J. C. Glaubitz, Q. Sun et al., "A robust, simple genotyping-by-sequencing (GBS) approach for high diversity species," PLoS ONE, vol. 6, no. 5, Article ID e19379, 2011.

[102] J. A. Poland, P. J. Brown, M. E. Sorrells, and J.-L. Jannink, "Development of high-density genetic maps for barley and wheat using a novel two-enzyme genotyping-by-sequencing approach," PLoS ONE, vol. 7, no. 2, Article ID e32253, 2012.

[103] X. Huang, X. Wei, T. Sang et al., "Genome-wide asociation studies of 14 agronomic traits in rice landraces," Nature Genetics, vol. 42, no. 11, pp. 961-967, 2010.

[104] A. A. Dahab, M. Saeed, B. B. Mohamed et al., "Genetic diversity assessment of cotton (Gossypium hirsutum L.) genotypes from Pakistan using simple sequence repeat marker," Australian Journal of Crop Science, vol. 7, no. 2, pp. 261-267, 2013.

[105] J. R. Russell, J. D. Fuller, M. Macaulay et al., "Direct comparison of levels of genetic variation among barley accessions detected by RFLPs, AFLPs, SSRs and RAPDs," Theoretical and Applied Genetics, vol. 95, no. 4, pp. 714-722, 1997.

[106] M. Pillay and G. O. Myers, "Genetic diversity in cotton assessed by variation in ribosomal RNA genes and AFLP markers," Crop Science, vol. 39, no. 6, pp. 1881-1886, 1999.

[107] I. Ullah, A. Iram, M. Z. Iqbal, M. Nawaz, S. M. Hasni, and S. Jamil, "Genetic diversity analysis of Bt cotton genotypes in Pakistan using simple sequence repeat markers," Genetics and Molecular Research, vol. 11, no. 1, pp. 597-605, 2012.

[108] M. Vafaie-Tabar, S. Chandrashekaran, R. P. Singh, and M. K. Rana, "Evaluation of genetic diversity in Indian tetraploid and diploid cotton (Gossypium spp.) by morphological characteristics and RAPDs," Indian Journal of Genetics and Plant Breeding, vol. 63, no. 3, pp. 230-234, 2003.

[109] S. S. Mehetre, M. Gomes, E. Susan, A. R. Aher, and G. C. Shinde, "RAPD and cytomorphological analyses of $\mathrm{F}_{1}, \mathrm{~F}_{2}$ and amphidiploid $\left(\mathrm{A}_{1}\right)$ generations of Gossypium arboreum $\times$ Gossypium capitis-viridis," Cytologia, vol. 69, no. 4, pp. 367-379, 2004.

[110] M. K. Rana, S. Singh, and K. V. Bhat, "RAPD, STMS and ISSR markers for genetic diversity and hybrid seed purity testing in cotton," Seed Science and Technology, vol. 35, no. 3, pp. 709-721, 2007. 
[111] M. Sheidai, F. Yahyazadeh, F. Farahanei, and Z. Noormohammad, "Genetic and morphological variations induced by tissue culture in tetraploid cotton (Gossypium hirsutum L.)," Acta Biologica Szegediensis, vol. 52, no. 1, pp. 33-38, 2008.

[112] M. Sheidai, L. Bahrami, A. Majd, Z. Noormohammadi, and O. Alishah, "Genetic diversity in F2 back-cross progenies of cotton," Gene Conserve, vol. 9, pp. 167-187, 2010.

[113] M. J. Iqbal, N. Aziz, N. A. Saeed, Y. Zafar, and K. A. Malik, "Genetic diversity evaluation of some elite cotton varieties by RAPD analysis," Theoretical and Applied Genetics, vol. 94, no. 1, pp. 139-144, 1997.

[114] X. Y. Wang, W. Z. Guo, T. Z. Zhang, and J. J. Pan, "Analysis of RAPD fingerprinting on short-seasonal cotton cultivars in China," Acta Agronomica Sinica, vol. 23, pp. 669-676, 1997.

[115] S. A. Khan, D. Hussain, E. Askari, J. M. Stewart, K. A. Malik, and Y. Zafar, "Molecular phylogeny of Gossypium species by DNA fingerprinting," Theoretical and Applied Genetics, vol. 101, no. 56, pp. 931-938, 2000.

[116] A. S. Mumtaz, M. Naveed, and Z. K. Shinwari, "Assessment of genetic diversity and germination pattern in selected cotton genotypes of Pakistan," Pakistan Journal of Botany, vol. 42, no. 6, pp. 3949-3956, 2010.

[117] I. Vroh Bi, A. Maquet, J. P. Baudoin, P. du Jardin, J. M. Jacquemin, and G. Mergeai, "Breeding for 'low-gossypol seed and high-gossypol plants' in upland cotton. Analysis of trispecies hybrids and backcross progenies using AFLPs and mapped RFLPs," Theoretical and Applied Genetics, vol. 99, no. 7-8, pp. 1233-1244, 1999.

[118] S. Saha, M. Karaca, J. N. Jenkins, A. E. Zipf, O. U. K. Reddy, and R. V. Kantety, "Simple sequence repeats as useful resources to study transcribed genes of cotton," Euphytica, vol. 130, no. 3, pp. 355-364, 2003.

[119] S. Liu, S. Saha, D. Stelly, B. Burr, and R. G. Cantrell, "Chromosomal assignment of microsatellite loci in cotton," Journal of Heredity, vol. 91, no. 4, pp. 326-332, 2000.

[120] O. A. Gutiérrez, S. Basu, S. Saha et al., "Genetic distance among selected cotton genotypes and its relationship with F2 performance," Crop Science, vol. 42, no. 6, pp. 1841-1847, 2002.

[121] D. Rungis, D. Llewellyn, E. S. Dennis, and B. R. Lyon, "Simple sequence repeat (SSR) markers reveal low levels of polymorphism between cotton (Gossypium hirsutum L.) cultivars," Australian Journal of Agricultural Research, vol. 56, no. 3, pp. 301-307, 2005.

[122] J. E. Frelichowski Jr., M. B. Palmer, D. Main et al., "Cotton genome mapping with new microsatellites from Acala "Maxxa" BAC-ends," Molecular Genetics and Genomics, vol. 275, no. 5, pp. 479-491, 2006.

[123] C. H. C. de Magalhães Bertini, I. Schuster, T. Sediyama, E. G. de Barros, and M. A. Moreira, "Characterization and genetic diversity analysis of cotton cultivars using microsatellites," Genetics and Molecular Biology, vol. 29, no. 2, pp. 321-329, 2006.

[124] G. Chen and X.-M. Du, "Genetic diversity of source germplasm of upland cotton in China as determined by SSR marker analysis," Acta Genetica Sinica, vol. 33, no. 8, pp. 733-745, 2006.

[125] X. Q. Wang, C. H. Feng, Z. X. Lin, and X. L. Zhang, "Genetic diversity of sea-island cotton (Gossypium barbadense) revealed by mapped SSRs," Genetics and molecular research : GMR, vol. 10, no. 4, pp. 3620-3631, 2011.

[126] D. D. Fang, L. L. Hinze, R. G. Percy, P. Li, D. Deng, and G. Thyssen, "A microsatellite-based genome-wide analysis of genetic diversity and linkage disequilibrium in Upland cotton
(Gossypium hirsutum L.) cultivars from major cotton-growing countries," Euphytica, vol. 191, no. 3, pp. 391-401, 2013.

[127] P. Selvakumar, R. Ravikesavan, A. Gopikrishnan, K. Thiyagu, S. Preetha, and N. M. Boopathi, "Genetic purity analysis of cotton (Gossypium spp.) hybrids using SSR markers," Seed Science and Technology, vol. 38, no. 2, pp. 358-366, 2010.

[128] B. C. Y. Collard, M. Z. Z. Jahufer, J. B. Brouwer, and E. C. K. Pang, "An introduction to markers, quantitative trait loci (QTL) mapping and marker-assisted selection for crop improvement: the basic concepts," Euphytica, vol. 142, no. 1-2, pp. 169-196, 2005.

[129] A. H. Paterson, "Making genetic maps," in Genome Mapping in Plants, pp. 23-39, RG Landes Company, Austin, Tex, USA; Academic Press, San Diego, Calif, USA, 1996.

[130] A. H. Paterson, "Mapping genes responsible for differences in phenotype," in Genome Mapping in Plants, pp. 41-54, R G Landes, San Diego, Calif, USA; Academic Press, Austin, Tex, USA, 1996.

[131] C.-X. Jiang, R. J. Wright, K. M. El-Zik, and A. H. Paterson, "Polyploid formation created unique avenues for response to selection in Gossypium (cotton)," Proceedings of the National Academy of Sciences of the United States of America, vol. 95, no. 8, pp. 4419-4424, 1998.

[132] R. J. Wright, P. M. Thaxton, K. M. El-Zik, and A. H. Paterson, "Molecular mapping of genes affecting pubescence of cotton," Journal of Heredity, vol. 90, no. 1, pp. 215-219, 1999.

[133] Y. Saranga, M. Menz, C.-X. Jiang, R. J. Wright, D. Yakir, and A. H. Paterson, "Genomic dissection of genotype $\mathrm{x}$ environment interactions conferring adaptation of cotton to arid conditions," Genome Research, vol. 11, no. 12, pp. 1988-1995, 2001.

[134] P. W. Chee, X. Draye, C. X. Jiang et al., "Molecular dissection of phenotypic variation between Gossypium hirsutum and Gossypium barbadense (cotton) by a backcross-self approach: III. Fiber length," Theoretical and Applied Genetics, vol. 111, no. 4, pp. 772-781, 2005.

[135] R. J. Kohel, J. Yu, Y.-H. Park, and G. R. Lazo, "Molecular mapping and characterization of traits controlling fiber quality in cotton," Euphytica, vol. 121, no. 2, pp. 163-172, 2001.

[136] X. Shen, W. Guo, X. Zhu et al., "Molecular mapping of QTLs for fiber qualities in three diverse lines in Upland cotton using SSR markers," Molecular Breeding, vol. 15, no. 2, pp. 169-181, 2005.

[137] B.-H. Wang, Y.-T. Wu, N.-T. Huang, X.-F. Zhu, W.-Z. Guo, and T.-Z. Zhang, "QTL mapping for plant architecture traits in upland cotton using RILs and SSR markers," Acta Genetica Sinica, vol. 33, no. 2, pp. 161-170, 2006.

[138] H. Qin, W. Guo, Y.-M. Zhang, and T. Zhang, “QTL mapping of yield and fiber traits based on a four-way cross population in Gossypium hirsutum L," Theoretical and Applied Genetics, vol. 117, no. 6, pp. 883-894, 2008.

[139] J. Z. Yu, R. J. Kohe, D. D. Fang et al., "A high-density simple sequence repeat and single nucleotide polymorphism genetic map of the tetraploid cotton genome," G3: Genes, Genomes, Genetics, vol. 2, no. 1, pp. 43-58, 2012.

[140] C. Li, X. Wang, N. Dong et al., "QTL analysis for early-maturing traits in cotton using two upland cotton (Gossypium hirsutum L.) crosses," Breeding Science, vol. 63, no. 2, pp. 154-163, 2013.

[141] M. Mei, N. H. Syed, W. Gao et al., "Genetic mapping and QTL analysis of fiber-related traits in cotton (Gossypium)," Theoretical and Applied Genetics, vol. 108, no. 2, pp. 280-291, 2004 . 
[142] M. Nordborg and S. Tavaré, "Linkage disequilibrium: what history has to tell us," Trends in Genetics, vol. 18, no. 2, pp. 83-90, 2002.

[143] S. Myles, J. Peiffer, P. J. Brown et al., "Association mapping: critical considerations shift from genotyping to experimental design," The Plant Cell, vol. 21, no. 8, pp. 2194-2202, 2009.

[144] C. Zhu, M. Gore, E. S. Buckler, and J. Yu, "Status and prospects of association mapping in plants," The Plant Genome, vol. 1, no. 1, pp. 5-20, 2008.

[145] I. Y. Abdurakhmonov, "Exploiting genetic diversity," in Proceedings of the World Cotton Research Conference, vol. 1, pp. 10-14, Lubbock, Tex, USA, 2007.

[146] A. Barnaud, T. Lacombe, and A. Doligez, "Linkage disequilibrium in cultivated grapevine, Vitis vinifera L," Theoretical and Applied Genetics, vol. 112, no. 4, pp. 708-716, 2006.

[147] I. Y. Abdurakhmonov, S. Saha, J. N. Jenkins et al., "Linkage disequilibrium based association mapping of fiber quality traits in G. hirsutum L. variety germplasm," Genetica, vol. 136, no. 3, pp. 401-417, 2009.

[148] D. Edwards and J. Batley, "Plant genome sequencing: applications for crop improvement," Plant Biotechnology Journal, vol. 8, no. 1, pp. 2-9, 2010.

[149] N. F. Weeden, G. M. Timmerman, and J. Lu, "Identifying and mapping genes of economic significance," Euphytica, vol. 73, no. 1-2, pp. 191-198, 1993.

[150] N. D. Young, "QTL mapping and quantitative disease resistance in plants," Annual Review of Phytopathology, vol. 34, pp. 479501, 1996.

[151] V. H. Coryell, H. Jessen, J. M. Schupp, D. Webb, and P. Keim, "Allele-specific hybridization markers for soybean," Theoretical and Applied Genetics, vol. 98, no. 5, pp. 690-696, 1999.

[152] G. Mergeai, J. P. Baudoin, and B. I. Vroh, "Production of high gossypol cotton plants with low gossypol seed from trispecific hybrids including Gossypium sturtianum," in proceedings of the World Cotton Research Conference, vol. 2, pp. 206-210, Athens, Greece, september 1998.

[153] T. Zhang, Y. Yuan, J. Yu, W. Guo, and R. J. Kohel, "Molecular tagging of a major QTL for fiber strength in upland cotton and its marker-assisted selection," Theoretical and Applied Genetics, vol. 106, no. 2, pp. 262-268, 2003.

[154] W. Guo, T. Zhang, X. Shen, J. Z. Yu, and R. J. Kohel, "Development of SCAR marker linked to a major QTL for high fiber strength and its usage in molecular-marker assisted selection in upland cotton," Crop Science, vol. 43, no. 6, pp. 2252-2256, 2003.

[155] D. D. Fang, J. Xiao, P. C. Canci, and R. G. Cantrell, "A new SNP haplotype associated with blue disease resistance gene in cotton (Gossypium hirsutum L.)," Theoretical and Applied Genetics, vol. 120, no. 5, pp. 943-953, 2010.

[156] G. Sunilkumar, L. M. Campbell, L. Puckhaber, R. D. Stipanovic, and K. S. Rathore, "Engineering cottonseed for use in human nutrition by tissue-specific reduction of toxic gossypol," Proceedings of the National Academy of Sciences of the United States of America, vol. 103, no. 48, pp. 18054-18059, 2006.

[157] B. Hendrix and J. M. Stewart, "Estimation of the nuclear DNA content of Gossypium species," Annals of Botany, vol. 95, no. 5, pp. 789-797, 2005.

[158] L. Lin, G. J. Pierce, J. E. Bowers et al., "A draft physical map of a D-genome cotton species (Gossypium raimondii)," BMC Genomics, vol. 11, no. 1, article 395, 2010.

[159] K. Wang, Z. Wang, F. Li et al., "The draft genome of a diploid cotton Gossypium raimondii," Nature Genetics, vol. 44, no. 10, pp. 1098-1103, 2012.
[160] F. Li, G. Fan, K. Wang et al., "Genome sequence of the cultivated cotton Gossypium arboreum," Nature Genetics, vol. 46, no. 6, pp. 567-572, 2014.

[161] P. Chee, E. Lubbers, O. May, J. Gannaway, and A. H. Paterson, "Changes in genetic diversity of the U.S. upland cotton," in Proceedings of the Beltwide Cotton Conference, National Cotton Council, San Antonio, Tex, USA, 2004.

[162] E. Lubbers, P. Chee, J. Gannaway, R. Wright, K. El-Zik, and A. H. Paterson, "Levels and patterns of genetic diversity in upland cotton," in Proceedings of the Plant and Animal Genome 12th Conference, San Diego, Calif, USA, 2004.

[163] H.-M. Wang, Z.-X. Lin, X.-L. Zhang et al., "Mapping and quantitative trait loci analysis of verticillium wilt resistance genes in cotton," Journal of Integrative Plant Biology, vol. 50, no. 2, pp. 174-182, 2008.

[164] C. Niu, H. E. Lister, B. Nguyen, T. A. Wheeler, and R. J. Wright, "Resistance to Thielaviopsis basicola in the cultivated a genome cotton," Theoretical and Applied Genetics, vol. 117, no. 8, pp. 13131323, 2008.

[165] C. Niu, D. J. Hinchliffe, R. G. Cantrell, C. Wang, P. A. Roberts, and J. Zhang, "Identification of molecular markers associated with root-knot nematode resistance in upland cotton," Crop Science, vol. 47, no. 3, pp. 951-960, 2007.

[166] V. Korzun, "Use of molecular markers in cereal breeding," Cellular and Molecular Biology Letters, vol. 7, no. 2, pp. 811-820, 2002.

[167] E. Jones, W.-C. Chu, M. Ayele et al., "Development of single nucleotide polymorphism (SNP) markers for use in commercial maize (Zea mays L.) germplasm," Molecular Breeding, vol. 24, no. 2, pp. 165-176, 2009.

[168] S. Deschamps, V. Llaca, and G. D. May, "Genotyping-bysequencing in plants," Biology, vol. 1, no. 3, pp. 460-483, 2012.

[169] T. Yasmin, N. Tabbasam, I. Ullah, M. Asif, and Y. Zafar, "Studying the extent of genetic diversity among Gossypium arboreum L. genotypes/cultivars using DNA fingerprinting," Genetic Resources and Crop Evolution, vol. 55, no. 3, pp. 331-339, 2008.

[170] Z. Noormohammadi, M. T. S. Al-Rubaye, M. Sheidai, and O. Alishah, "ISSR, RAPD and agronomic study in some $\mathrm{F}_{1}$ and $\mathrm{F}_{2}$ cotton genotypes," Acta Biologica Szegediensis, vol. 55, no. 2, pp. 219-225, 2011.

[171] A. B. Dongre, M. P. Raut, V. M. Paikrao, and S. S. Pande, "Genetic purity testing of cotton F1 hybrid DHH-11 and parents revealed by molecular markers," International Research Journal of Biotechnology, vol. 3, no. 2, pp. 32-36, 2012.

[172] Z. Noormohammadi, Y. H.-A. Farahani, M. Sheidai, S. G. Baraki, and O. Alishah, "Genetic diversity analysis in Opal cotton hybrids based on SSR, ISSR, and RAPD markers," Genetics and Molecular Research, vol. 12, no. 1, pp. 256-269, 2013.

[173] J. Zhang, Y. Lu, R. G. Cantrell, and E. Hughs, "Molecular marker diversity and field performance in commercial cotton cultivars evaluated in the southwestern USA," Crop Science, vol. 45, no. 4, pp. 1483-1490, 2005.

[174] D. Liu, X. Guo, Z. Lin, Y. Nie, and X. Zhang, "Genetic diversity of Asian cotton (Gossypium arboreum L.) in China evaluated by microsatellite analysis," Genetic Resources and Crop Evolution, vol. 53, no. 6, pp. 1145-1152, 2006.

[175] W.-Z. Guo, B.-L. Zhou, L.-M. Yang, W. Wang, and T.-Z. Zhang, "Genetic diversity of landraces in Gossypium arboreum L. Race sinense assessed with simple sequence repeat markers," Journal of Integrative Plant Biology, vol. 48, no. 9, pp. 1008-1017, 2006. 
[176] J.-M. Lacape, D. Dessauw, M. Rajab, J.-L. Noyer, and B. Hau, "Microsatellite diversity in tetraploid Gossypium germplasm: assembling a highly informative genotyping set of cotton SSRs," Molecular Breeding, vol. 19, no. 1, pp. 45-58, 2007.

[177] S. K. Kantartzi, M. Ulloa, E. Sacks, and J. M. Stewart, "Assessing genetic diversity in Gossypium arboreum L. cultivars using genomic and EST-derived microsatellites," Genetica, vol. 136, no. 1, pp. 141-147, 2009.

[178] A. Qayyum, N. Murtaza, F. M. Azhar, and W. Malik, "Biodiversity and nature of gene action for oil and protein contents in Gossypium hirsutum L. estimated by SSR markers," Journal of Food, Agriculture and Environment, vol. 7, no. 2, pp. 590-593, 2009.

[179] Y. Zhang, X. F. Wang, Z. K. Li, G. Y. Zhang, and Z. Y. $\mathrm{Ma}$, "Assessing genetic diversity of cotton cultivars using genomic and newly developed expressed sequence tag-derived microsatellite markers," Genetics and Molecular Research, vol. 10, no. 3, pp. 1462-1470, 2011.

[180] A. Kalivas, F. Xanthopoulos, O. Kehagia, and A. S. Tsaftaris, "Agronomic characterization, genetic diversity and association analysis of cotton cultivars using simple sequence repeat molecular markers," Genetics and Molecular Research, vol. 10, no. 1, pp. 208-217, 2011.

[181] P. Tyagi, M. A. Gore, D. T. Bowman, B. T. Campbell, J. A. Udall, and V. Kuraparthy, "Genetic diversity and population structure in the US Upland cotton (Gossypium hirsutum L.)," Theoretical and Applied Genetics, vol. 127, pp. 283-295, 2013.

[182] M. K. Rana, V. P. Singh, and K. V. Bhat, "Assessment of genetic diversity in upland cotton (Gossypium hirsutum L.) breeding lines by using amplified fragment length polymorphism (AFLP) markers and morphological characteristics," Genetic Resources and Crop Evolution, vol. 52, no. 8, pp. 989-997, 2005.

[183] O. T. Westengen, Z. Huamán, and M. Heun, "Genetic diversity and geographic pattern in early South American cotton domestication," Theoretical and Applied Genetics, vol. 110, no. 2, pp. 392-402, 2005.

[184] S. Ahmad, T. Zhang, N. Islam, S. Tayyaba, and M. Rahman, "Identifying genetic variation in Gossypium based on single nucleotide polymorphism," Pakistan Journal of Botany, vol. 39, no. 4, pp. 1245-1250, 2007.

[185] X. Draye, P. Chee, C.-X. Jiang et al., "Molecular dissection of interspecific variation between Gossypium hirsutum and G. barbadense (cotton) by a backcross-self approach: II. Fiber fineness," Theoretical and Applied Genetics, vol. 111, no. 4, pp. 764-771, 2005.

[186] Z.-S. Zhang, M.-C. Hu, J. Zhang et al., "Construction of a comprehensive PCR-based marker linkage map and QTL mapping for fiber quality traits in upland cotton (Gossypium hirsutum L.)," Molecular Breeding, vol. 24, no. 1, pp. 49-61, 2009.

[187] B. Wang, W. Guo, X. Zhu, Y. Wu, N. Huang, and T. Zhang, "QTL mapping of fiber quality in an elite hybrid derived-RIL population of upland cotton," Euphytica, vol. 152, no. 3, pp. 367$378,2006$.

[188] K. Zhang, J. Zhang, J. Ma et al., "Genetic mapping and quantitative trait locus analysis of fiber quality traits using a three-parent composite population in upland cotton (Gossypium hirsutum L.)," Molecular Breeding, vol. 29, no. 2, pp. 335-348, 2012.

[189] J. Wu, O. A. Gutierrez, J. N. Jenkins, J. C. McCarty, and J. Zhu, "Quantitative analysis and QTL mapping for agronomic and fiber traits in an RI population of upland cotton," Euphytica, vol. 165, no. 2, pp. 231-245, 2009.
[190] X. Shen, W. Guo, Q. Lu, X. Zhu, Y. Yuan, and T. Zhang, "Genetic mapping of quantitative trait loci for fiber quality and yield trait by RIL approach in upland cotton," Euphytica, vol. 155, no. 3, pp. 371-380, 2007.

[191] R. Liu, B. Wang, W. Guo et al., "Quantitative trait loci mapping for yield and its components by using two immortalized populations of a heterotic hybrid in Gossypium hirsutum L," Molecular Breeding, vol. 29, no. 2, pp. 297-311, 2012.

[192] D. H. He, Z. X. Lin, X. L. Zhang et al., "QTL mapping for economic traits based on a dense genetic map of cotton with PCR-based markers using the interspecific cross of Gossypium hirsutum x Gossypium barbadense," Euphytica, vol. 153, no. 1-2, pp. 181-197, 2007.

[193] C. Jiang, R. J. Wright, S. S. Woo, T. A. DelMonte, and A. H. Paterson, "QTL analysis of leaf morphology in tetraploid Gossypium (cotton)," Theoretical and Applied Genetics, vol. 100, no. 3-4, pp. 409-418, 2000.

[194] Y. Guo, J. C. McCarty, J. N. Jenkins, and S. Saha, "QTLs for node of first fruiting branch in a cross of an upland cotton, Gossypium hirsutum L., cultivar with primitive accession Texas 701," Euphytica, vol. 163, no. 1, pp. 113-122, 2008.

[195] R. M. D. Koebner and R. W. Summers, "21st century wheat breeding: plot selection or plate detection?" Trends in Biotechnology, vol. 21, no. 2, pp. 59-63, 2003. 

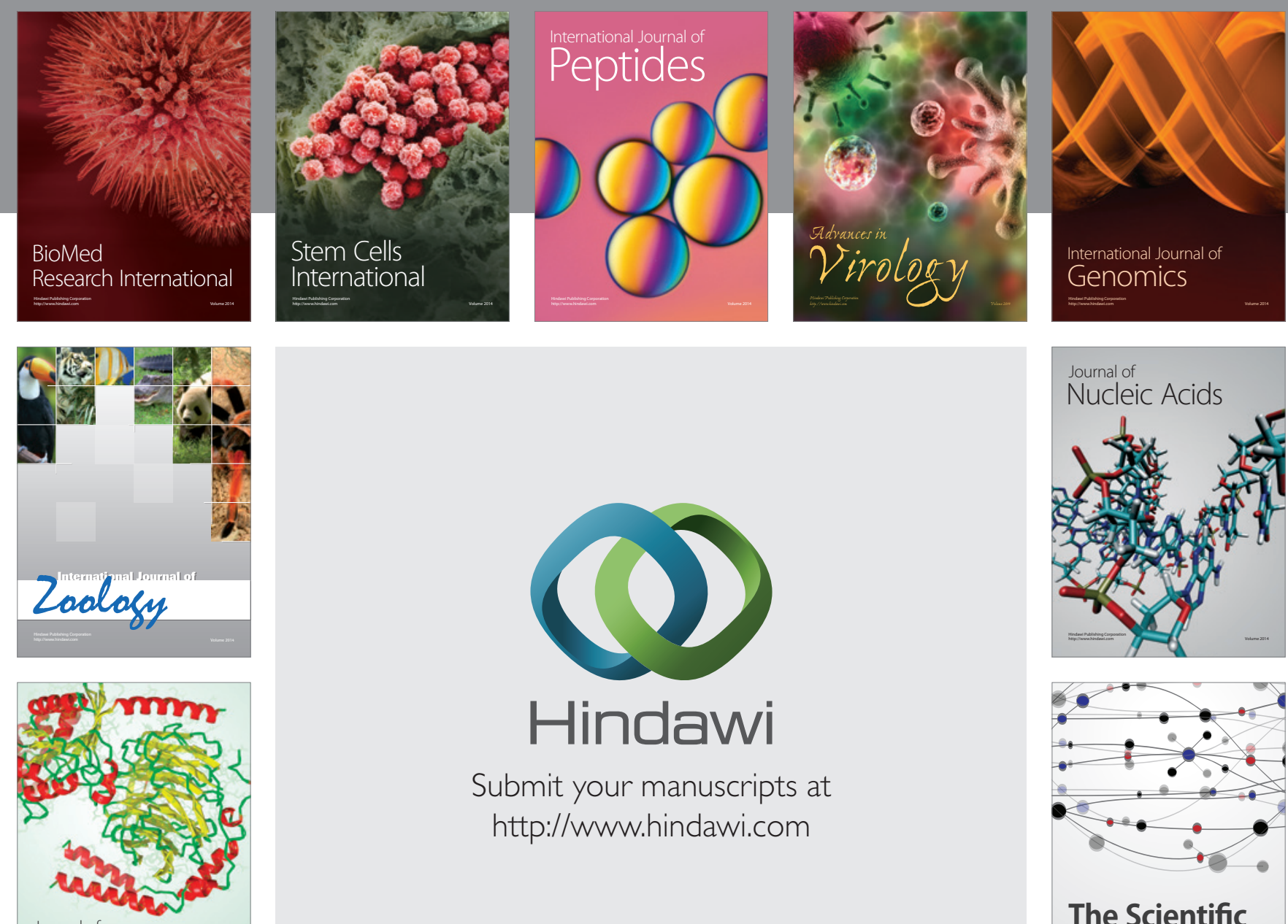

Submit your manuscripts at

http://www.hindawi.com

Journal of
Signal Transduction
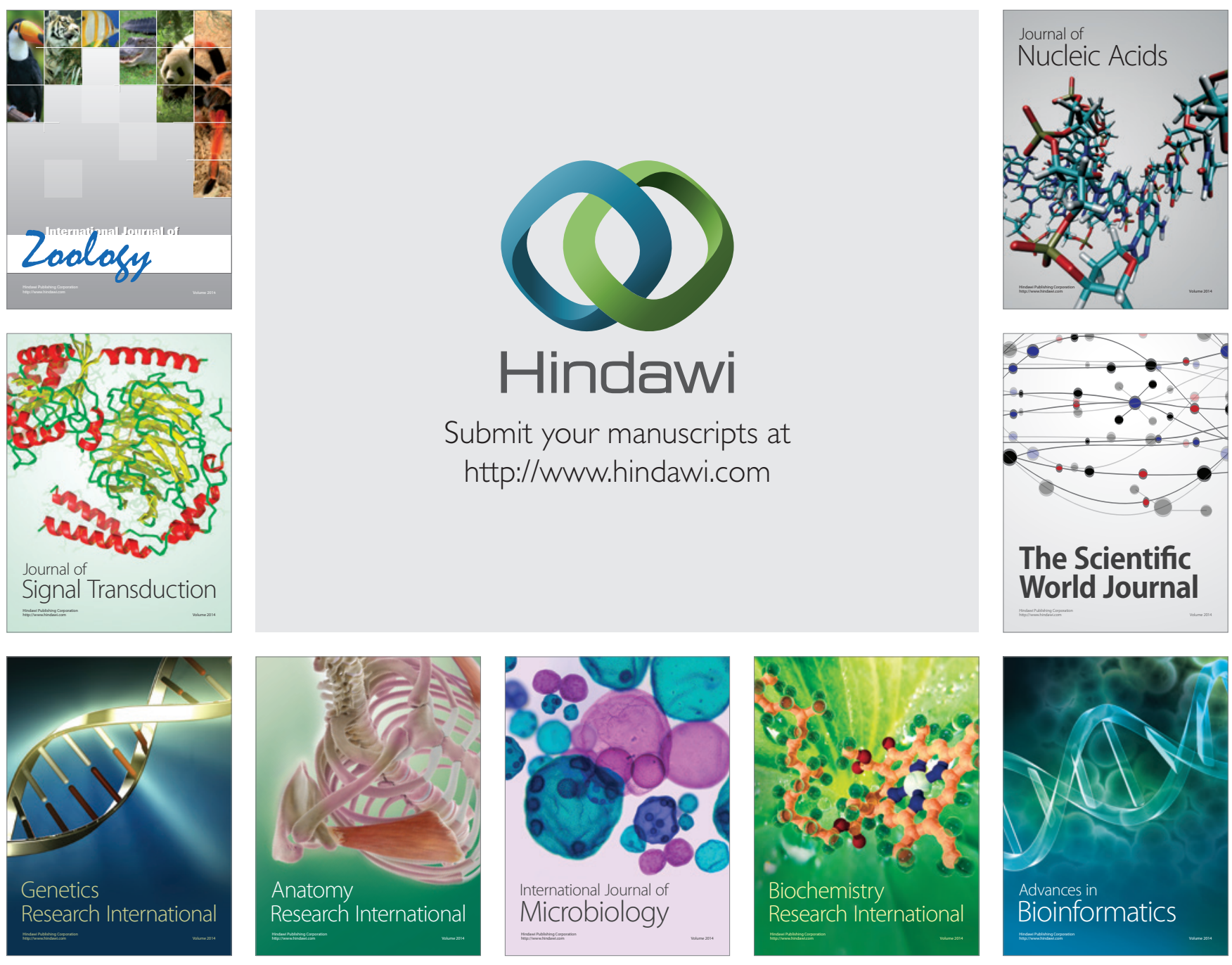

The Scientific World Journal
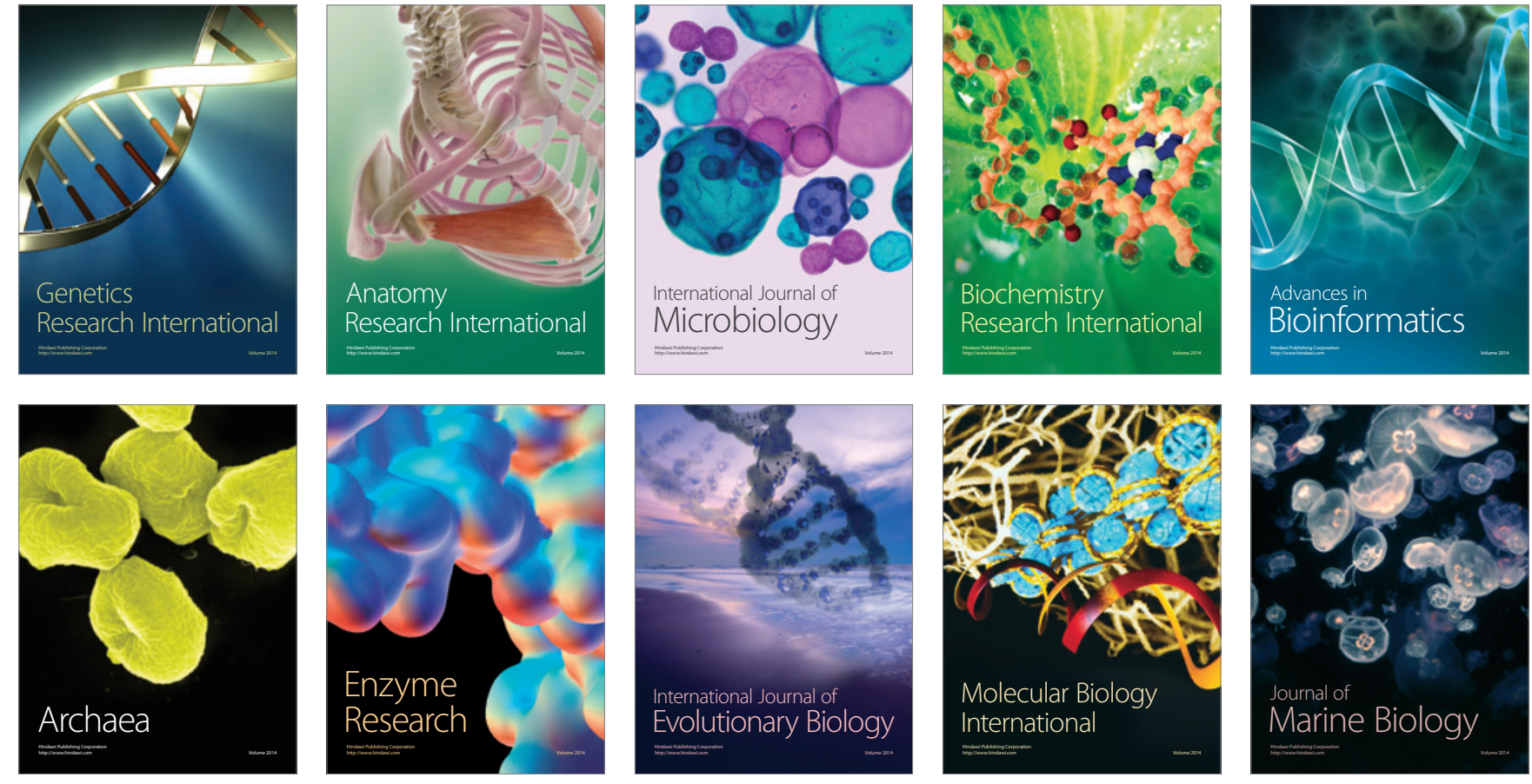